\title{
The Interaction between Ovomucin and Egg White Proteins
}

\author{
Akio Kato, Kiyoko Yoshida, Naotoshi Matsudomi \\ and Kunihiko KoBAYASHI \\ Department of Agricultural Chemistry, Faculty of Agriculture, \\ Yamaguchi University, Yamaguchi, Japan
}

Received June 2, 1976

\begin{abstract}
The interaction between ovomucin and egg white proteins has been investigated. Ovomucin interacted not only with lysozyme but also with such proteins in egg white as ovalbumin and conalbumin. The interaction increased correspondingly as the lysine content of proteins become higher. The maximum turbidity of ovomucin-lysozyme aggregates was proportionally dependent on the rate of acetylation of lysozyme, but that of ovomucin-ovalbumin aggregates was slightly dependent on the rate of acetylation of ovalbumin. The ovomucin-protein interaction decreased remarkably by the removal of sialic acid in ovomucin, but increased by the removal of polyhydroxyl group in sialic acid. From these results, the binding site of interaction was considered in detail.
\end{abstract}

The ovomucin-lysozyme interaction is considered to be important to form the rigid gelatinous structure in the thick white. ${ }^{1,2}$ This interaction was suggested by some workers to be due to the electrostatic interaction between the negative charges of ovomucin molecules and the positive charges of lysozyme molecules. $^{3,4)}$ In the previous report, ${ }^{5)}$ it was confirmed that the interaction between the terminal sialic acid of ovomucin and the lysyl amino group of lysozyme is essential for the ovomucinlysozyme interaction. Thus, the binding groups in ovomucin-lysozyme interaction were identified.

However, it is probable that ovomucin interacts not only with lysozyme but also with some other proteins in egg white, because most of proteins contain a considerable extent of lysyl amino groups. This paper describes whether ovomucin interacts specifically with lysozyme or generally with some proteins in egg white. Further, the binding groups in ovomucinprotein interaction have been studied in detail.

\section{MATERIALS AND METHODS}

Materials. A lysozyme preparation isolated from hen's egg white by the direct crystallization method was recrystallized five times and lyophilized. An ovalbumin preparation isolated from hen's egg white by the sodium sulfate crystallization method was recrystallized five time and lyophilized. Conalbumin was isolated from hen's egg white by chromatography on a DEAEcellulose column, followed by gel-filtration on a BioGel P 100 column. Gelatin was a product from Katayama Chemical Industries Co. Pronase was a product from Kaken Chemical Co. Neuraminidase from $\mathrm{Cl}$. perfringens was a product of Sigma Chemical Co. All other reagents employed were analytical grade.

Preparation of ovomucin The procedure employed to prepare ovomucin was described previously. ${ }^{\circ}$ The fresh thick white was separated into gel and sol parts by ultracentrifugation for $60 \mathrm{~min}$ at $59,000 \times \mathrm{g}$. The gel part was washed directly with $2 \% \mathrm{KCl}$ without diluting with water until the washing was free from proteins. The gel-like precipitate was finally washed with water until the washing was free from chloride. Ovomucin thus obtained was solubilized by $0.01 \mathrm{M}$ mercaptoethanol in carbonate buffer ( $\mathrm{pH} 9.6$, ionic strength 0.25 ). After solubilization, ovomucin was dialyzed against one hundred volumes of $1 / 15 \mathrm{M}$ phosphate buffer ( $\mathrm{pH}$ 5.4). The reduced ovomucin solution thus obtained was employed in the following experiments.

Action of enzymes on ovomucin. To a $0.5 \%$ solution of reduced ovomucin was added $0.01 \%$ pronase, and the mixtures were incubated at $30^{\circ} \mathrm{C}$ for $4 \mathrm{hr}$ in $0.05 \mathrm{M}$ Tris- $\mathrm{HCl}$ buffer ( $\mathrm{pH} 8.0$ ).

Five $\mu \mathrm{g}$ of neuraminidase ( 2 units $/ \mathrm{mg}$ ) were added to $10 \mathrm{ml}$ of a $0.2 \%$ solution of reduced ovomucin. Enzymatic action was carried out at $30^{\circ} \mathrm{C}$ for $24 \mathrm{hr}$ in $1 / 15 \mathrm{M}$ phosphate buffer ( $\mathrm{pH} 5.4$ ).

Periodate oxidation of ovomucin. To $10 \mathrm{ml}$ of an ovomucin solution $(1 \mathrm{mg} / \mathrm{ml})$ was added $0.1 \mathrm{ml}$ of $0.2 \mathrm{M}$ 
periodate. The reaction mixtures were allowed to stand at $5^{\circ} \mathrm{C}$ in the dark for $2 \mathrm{hr}$. The samples were dialyzed against water for $24 \mathrm{hr}$. Then, to the oxidated samples was added $0.1 \mathrm{ml}$ of a freshly prepared solution of $1 \mathrm{M}$ sodium borohydride in $0.1 \mathrm{M}$ carbonate buffer (pH 9.6). The mixtures were kept at $5^{\circ} \mathrm{C}$ for $2 \mathrm{hr}$. Excess borohydride was destroyed by slowly adding acetic acid to $\mathrm{pH} 4.5$. The samples thus obtained were repeatedly dialyzed against water.

Acetylation of proteins. Acetylation of proteins was carried out as previously described. ${ }^{5 ?}$ To a mixture of $10 \mathrm{ml}$ of a $5 \%$ aqueous protein solution and $10 \mathrm{ml}$ of a saturated sodium acetate solution was added dropwise $5 \mathrm{~g}$ of acetic anhydride over a period of $1 \mathrm{hr}$ at $0^{\circ} \mathrm{C}$. The extent of acetylation was determined spectrophotometrically using a specific reagent for amino groups, trinitrobenzenesulfonate, according to the method described by Haynes et al. ${ }^{7}$ )

Measurement of the extent of ovomucin-protein interaction. One fifth $\mathrm{ml}$ of $0.2 \%$ reduced ovomucin solution was added to $2 \mathrm{ml}$ of $0.1 \%$ protein solution in $1 / 15 \mathrm{M}$ phosphate buffer or citrate buffer containing $0.1 \%$ gelatin. The turbidity of ovomucin-protein aggregation was stabilized by addition of $0.1 \%$ gelatin. The mixture was shaked and allowed to stand at $20^{\circ} \mathrm{C}$. After 20 min, turbidity was determined by measuring absorbances at $550 \mathrm{~nm}$. The extent of ovomucinprotein interaction was shown as percentages of the maximum turbidity of the ovomucin-protein mixture at low $\mathrm{pH}$.

Chemical analysis. Hexose content of ovomucin was determined by the orcinol method in which an equimolar mixture of galactose and mannose was used as the standard.8) Hexosamine content was determined by Elson-Morgan's method, as modified by Neuhaus et al., in which an equimolar mixture of galactosamine and glucosamine was used as the standard. ${ }^{\text {?) }}$ Sialic acid content was determined by the method described by Suttajit et al., by gas-liquid chromatography of the trimethylsilyl derivatives of sialic acid. ${ }^{10}$

\section{RESULTS AND DISCUSSION}

Non-specific interaction of ovomucin with egg white proteins

Ovomucin itself did not become turbid at low $\mathrm{pH}$ in the $0.018 \%$ solution used in the experiments. Protein itself did not also become turbid in the acid solution. On the other hand, the ovomucin-protein mixtures became turbid in the acid solution, as shown in Fig. 1. Therefore, the turbidity thus developed is

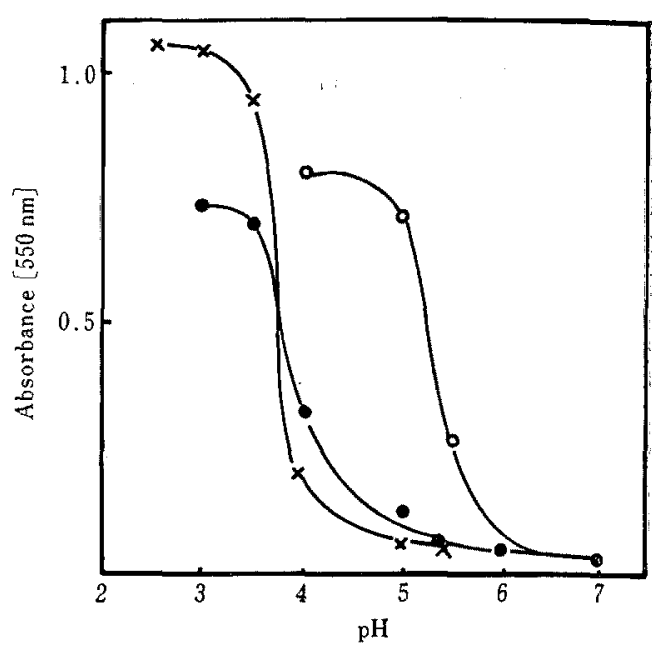

Fig. 1. Effect of pH on Ovomucin-protein Aggregation.

O-O, ovomucin-lysozyme aggregation; $\bullet-\bullet$, ovomucin-ovalbumin aggregation; $x-x$, ovomucinconalbumin aggregation.

considered to reflect the ovomucin-protein interaction. As shown in Fig. 1, ovomucin interacted with some proteins used in the experiments, but the maximum turbidity and the critical $\mathrm{pH}$ of ovomucin-protein aggregates differed from one another among the proteins. The maximum turbidity of the ovomucinconalbumin aggregates was higher than that of the ovomucin-lysozyme aggregates. Thus, it was confirmed that ovomucin interacts nonspecifically with some proteins even if the extent of interaction differed.

\section{Role of amino groups of protein in ovomucin- protein interaction}

It was shown in the previous report that the lysyl amino groups in lysozyme are essential for the ovomucin-lysozyme interaction, because the interaction was markedly affected by the chemical modification of lysyl amino groups in lysozyme. ${ }^{5)}$ As shown in Fig. 2, the maximum turbidity of the ovomucin-protein aggregates at low $\mathrm{pH}$ increased correspondingly as the lysine content of proteins became higher. This result suggests that the lysyl amino groups in protein play an important part for the ovomucin-protein interaction in common to all proteins. This has also been well confirmed 


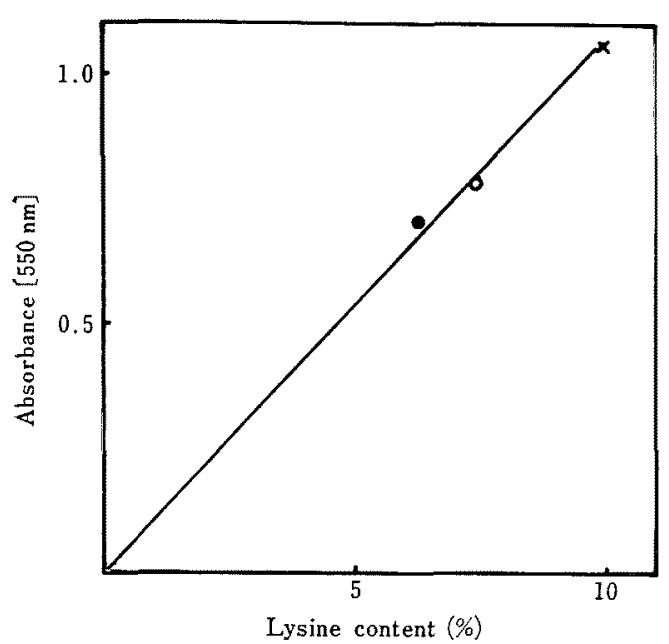

FIG. 2. Relation between Lysine Content of Protein and Ovomucin-protein Aggregation.

O, maximum turbidity of ovomucin-lysozyme aggregation; - maximum turbidity of ovomucinovalbumin aggregation; $x$, maximum turbidity of ovomucin-conalbumin aggregation.

by the results in Tables I and II. The maximum turbidity of the ovomucin-lysozyme aggregates decreased correspondingly as the acetylation of lysozyme or ovalbumin progressed. The maximum turbidity of ovomucin-lysozyme aggregates was proportionally dependent on the rate of acetylation of lysozyme. On the other hand, the maximum turbidity of ovomucin-ovalbumin aggregates was only slightly dependent on the rate of acetylation of ovalbumin. When 76 per cents of amino groups in ovalbumin were acetylated, about five residues of lysine remained unreacted in a mole of ovalbumin, as about twenty residues of lysine are contained in a mole of ovalbumin. In the previous report, ${ }^{5}$ ) it was shown that only two lysyl amino groups in a mole of lysozyme may be necessary for the ovomucin-lysozyme interaction. Therefore, if two lysyl amino groups in a mole of ovalbumin are necessary for ovomucin-ovalbumin interaction as well as for ovomucinlysozyme interaction, the extent of ovomucinovalbumin interaction seems to be not necessarily dependent on the rate of acetylation of ovalbumin. If the higher rate of acetylation of ovalbumin could be performed, the ovomucinovalbumin interaction would be more markedly
Table I. EFFect of ACETylation of Lysozyme ON OVOMUCIN-LYSOZYME AGGREGATION

\begin{tabular}{lcc}
\hline Lysozyme & $\begin{array}{c}\text { Percentages } \\
\text { of } \\
\text { free } \\
\text { amino group }\end{array}$ & $\begin{array}{c}\text { Maximum tur- } \\
\text { ovomucin-lysozyme } \\
\text { biggregates }\end{array}$ \\
\hline Control & 100 & 100 \\
Acetylated I & 70 & 59 \\
Acetylated II & 50 & 42 \\
\hline a) & Percentages of maximum turbidity of ovomucin- \\
& lysozyme mixture.
\end{tabular}

Table II. EFFect of Acetylation of Ovalbumin on OVOMUCIN-OValbumin Aggregation

\begin{tabular}{lcc} 
Ovalbumin & $\begin{array}{c}\text { Percentages } \\
\text { of free } \\
\text { amino group }\end{array}$ & $\begin{array}{c}\text { Maximum } \\
\text { turbidity of } \\
\text { ovomucin-oval- } \\
\text { bumin aggregates }\end{array}$ \\
\hline Control & 100 & 100 \\
Acetylated I & 44 & 73 \\
Acetylated II & 32 & 62 \\
Acetylated III & 24 & 52 \\
\hline
\end{tabular}

a) Percentages of maximum turbidity of ovomucinovalbumin mixture.

affected by the acetylation of ovalbumin. But, ovalbumin acetylated over 80 per cents could not be obtained because of insolubility of acetylated ovalbumin. On the other hand, the maximum turbidity of ovomucin-lysozyme aggregates was dependent on the rate of acetylation of lysozyme, as shown in Table I, because only six residues of lysine are contained in a mole of lysozyme. Thus, it was suggested that the lysyl amino groups in protein are essential for the ovomucin-protein interaction.

However, if only lysyl amino groups in protein are responsible for the ovomucinprotein interaction, the critical $\mathrm{pH}$ of the ovomucin-protein aggregates must be identical in common to all proteins. As shown in Fig. 1, it differed from one another among the proteins used in the experiments. This suggests that not only lysyl amino groups but also net electric charges of protein molecules are responsible for the ovomucin-protein interaction.

Role of sialic acid of ovomucin in ovomucinprotein interaction

It was shown in the previous report ${ }^{5}$ that the sialic acid of ovomucin is essential for the 


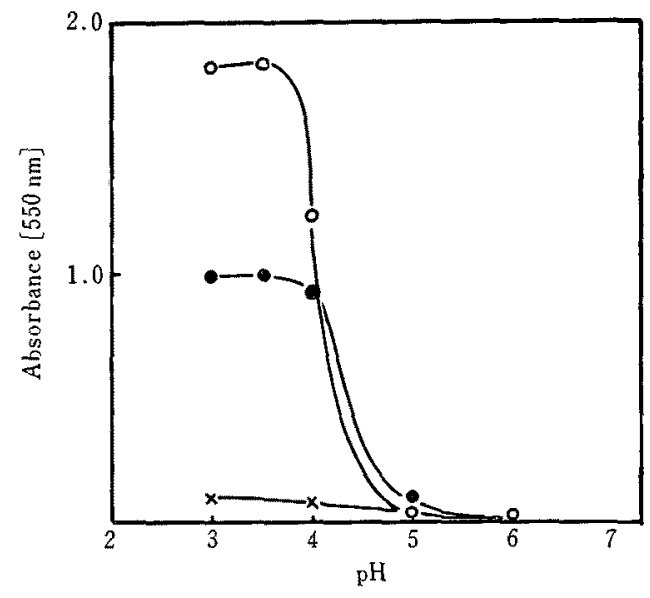

FIG. 3. Effect of Enzymatic Action for Ovomucin on Ovomucin-ovalbumin Aggregation.

- ovomucin; $0-0$, pronase action on ovomucin, $x-x$, neuraminidase action on ovomucin.

ovomucin-lysozyme interaction because the interaction was markedly affected by the removal of sialic acid. As shown in Fig. 3, the ovomucin-ovalbumin interaction decreased markedly by the enzymatic removal of sialic acid and increased by the action of pronase on ovomucin. It was also the case for the ovomucin-lysozyme interaction. This result suggests that the sialic acid in ovomucin is commonly essential for the ovomucin-protein interaction. The increase of interaction by the action of pronase on ovomucin may reflect the fact that the sialic acid residues were exposed outside. In fact, it was shown in the previous report ${ }^{112}$ that ovomucin is relatively resistant to pronase and only a part of protein portion is digested but the carbohydrate portion remains to be in macromolecules. Thus, it was suggested that the terminal sialic acid of ovomucin interacts with some proteins in common. However, there is no direct evidence for the binding site in sialic acid. Either the carboxyl group or the polyhydroxyl group of sialic acid is assumed to be the binding site. Suttajit and Winziler ${ }^{10)}$ have previously shown that the polyhydroxyl side chain of sialic acid can be selectively shortened to 8- and 7-carbon analogues (Fig. 4) by oxidation with very low amounts of periodate followed by borohydride reduction. This modification was applied to study the effect of the polyhydroxyl group on ovomucin-protein interaction. As shown in Table III, the trimethylsilyl derivatives of sialic

Table III. Changes of Chemical Composition by Oxidation with Perjodate of Ovomucin

\begin{tabular}{lccc}
\hline \multirow{2}{*}{ Ovomucin } & \multicolumn{3}{c}{ Content $^{a)}$} \\
\cline { 2 - 4 } & Hexose & Hexosamine & Sialic acid \\
\hline $\begin{array}{l}\text { Control } \\
\begin{array}{l}\text { Oxidated } \\
\left(2 \mathrm{mM} \mathrm{IO}_{4}^{-}\right)\end{array}\end{array}$ & 100 & 100 & 100 \\
$\begin{array}{l}\text { Oxidated } \\
\left(20 \mathrm{mM} \mathrm{IO}_{4}^{-}\right)\end{array}$ & 103 & 107 & 0 \\
\hline
\end{tabular}

a) Values were shown as percentages of the content of control ovomucin.

acid were not detected by gas-liquid chromatography after oxidation with $2 \mathrm{~mm}$ periodate followed by borohydride reduction of ovomucin. On the other hand, the other carbohydrates than sialic acid were not destroyed by oxidation with periodate followed by borohydride reduction of ovomucin, even at a 10-fold concentration of periodate. The ovo-

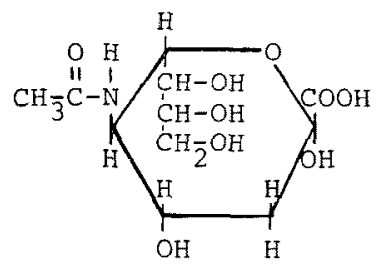

Sialic acid
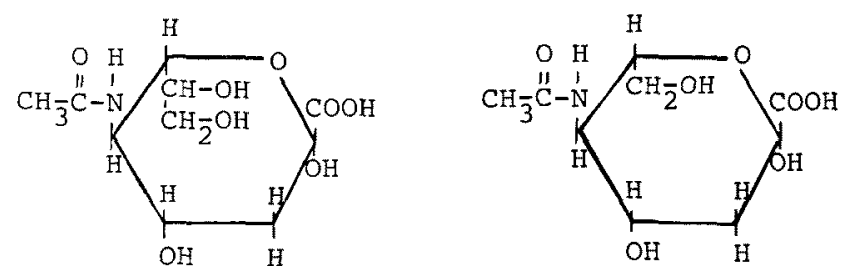

Sialic acid 8- and 7-carbon analogues

FIG. 4. The Structure of Sialic Acid and Its 8- and 7-carbon Analogues Produced by Oxidation with Periodate Followed by Borohydride Reduction. 


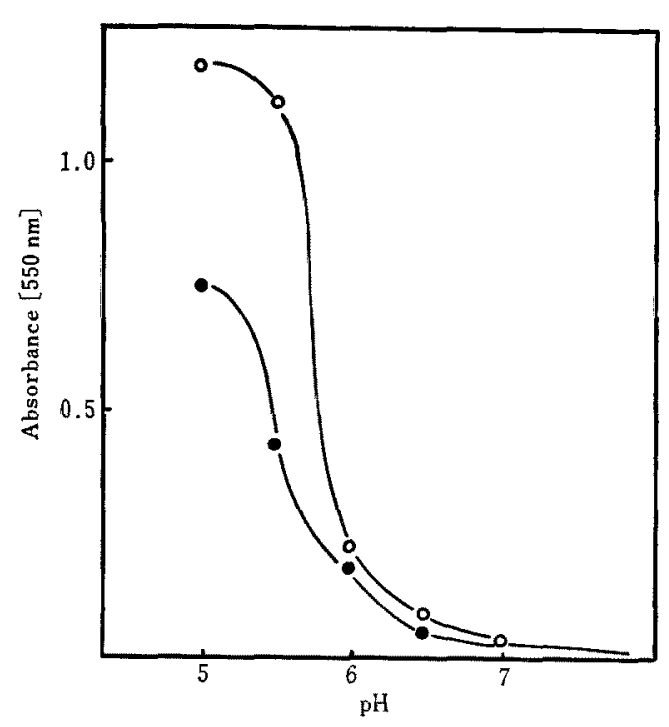

FIG. 5. Effect of Oxidation of Ovomucin with $\mathrm{NaIO}_{4}$ on Ovomucin-lysozyme Aggregation.

- - , ovomucin; $\mathrm{O}-\mathrm{O}$, oxidated ovomucin.

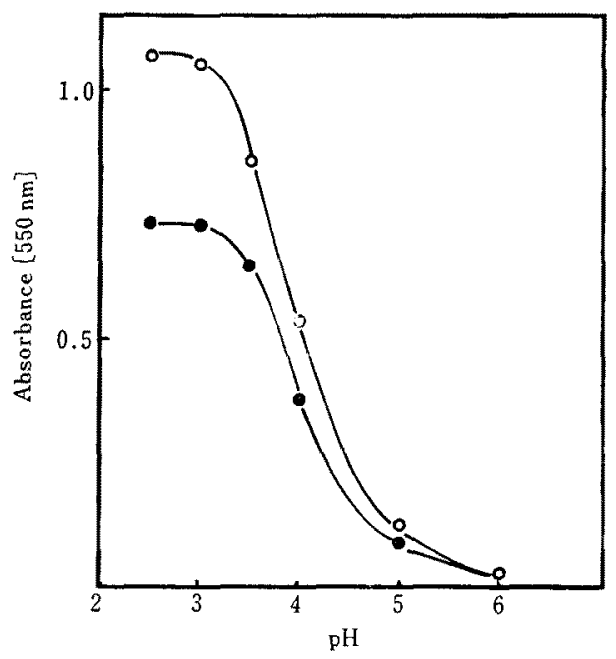

FIG. 6. Effect of Oxidation of Ovomucin with $\mathrm{NaIO}_{4}$ on Ovomucin-ovalbumin Aggregation.

-- ovomucin; O-O, oxidated ovomucin.

mucin-lysozyme and ovomucin-ovalbumin interaction were markedly increased by oxidation of ovomucin with periodate, as shown in Figs. 5 and 6 , respectively. The reaction rate of ovomucin-protein aggregation was also increased by oxidation of ovomucin with periodate, as shown in Table IV. It is interesting that the interaction was decreased by the re-
Table IV. EFFect of Oxidation of Ovomucin with Periodate on the Reaction rate of Ovomucin-ProteIn AGgregation

\begin{tabular}{lc}
\hline \multicolumn{1}{c}{$\begin{array}{c}\text { Ovomucin-protein } \\
\text { aggregation }\end{array}$} & $\begin{array}{c}\text { Relative reaction } \\
\text { rate }\end{array}$ \\
\hline Ovomucin-lysozyme & 1.0 \\
Oxidated ovomucin-lysozyme & 1.7 \\
Ovomucin-ovalbumin & 1.0 \\
Oxidated ovomucin-ovalbumin & 2.0 \\
\hline
\end{tabular}

a) Values were shown as ratio of the reaction rate of ovomucin-protein aggregation. The reaction rate of aggregation was shown as the increase of turbidity in initial $60 \mathrm{sec}$.

moval of sialic acid but increased by the removal of the polyhydroxyl group in sialic acid. These results suggest that the polyhydroxyl group of sialic acid is not essential for the ovomucin-protein interaction but hinders partially its interaction. It is probable from the steric model of sialic acid that the carboxyl group of sialic acid is partially concealed by the polyhydroxyl group and exposed by the removal of the polyhydroxyl group. Therefore, the increase of ovomucin-protein interaction by oxidation of ovomucin with periodate may be resulted from the exposure of the carboxyl group by the removal of the polyhydroxyl group. Thus, the carboxyl group of sialic acid is assumed to be the binding site for the ovomucin-protein interaction.

It has been proved that ovomucin interacts with the major proteins of egg white. However, the other proteins than lysozyme may not interact with ovomucin in the thick white, because these proteins could interact only at low $\mathrm{pH}$. But, the acid preparation method, in which ovomucin is precipitated at low $\mathrm{pH}$, should be avoided in the preparation of pure ovomucin. It is interesting that such a sialoglycoprotein as ovomucin interacts generally with some proteins and only sialic acid is essential for the interaction, although ovomucin contains a considerable amount of sulfate residues as the negative charge.

\section{REFERENCES}

1) J. Brooks and H. P. Hale, Biochim. Biophys. Acta, 32, 237 (1959). 
2) J. Brooks and H. P. Hale, Biochim. Biophys. Acta, 46, 289 (1961).

3) O. J. Cotterill and A. R. Winter, Poultry Sci., 34, 679 (1955).

4) D. S. Robinson and J. B. Monsey, J. Sci. Food Agr., 23, 893 (1972).

5) A. Kato, T. Imoto and K. Yagishita, Agr. Biol. Chem., 39, 541 (1975).

6) A. Kato, R. Nakamura and Y. Sato, ibid., 34, 1009 (1970).
7) R. Haynes, D. T. Osuga and R. E. Feeney, Biochemistry, 6, 541 (1967).

8) N. L. Allport, "Colorimetric Analysis," Vol. 1, Chapman and Hall Ltd., 1957, p. 82.

9) O. W. Neuhaus and M. Letzring, Anal. Chem., 29, 1230 (1957).

10) M. Suttajit and R. J. Winzler, J. Biol. Chem., 246, 3398 (1971).

11) A. Kato, K. Fujinaga and K. Yagishita, Agr, Biol. Chem., 37, 2479 (1973). 